\title{
Surgical outcomes in spinal cord ependymomas and the importance of extent of resection in children and young adults
}

\author{
Clinical article
}

\author{
*Michael Safaee, B.S., ${ }^{1}$ Michael C. Oh, M.D., Ph.D., ${ }^{1}$ Praveen V. Mummaneni, M.D., ${ }^{1}$ \\ Philip R. Weinstein, M.D., ${ }^{1}$ Christopher P. Ames, M.D., ${ }^{1}$ Dean Chou, M.D.,${ }^{1}$ \\ Mitchel S. Berger, M.D., ${ }^{1}$ Andrew T. Parsa, M.D., Ph.D., ${ }^{3}$ \\ and Nalin Gupta, M.D., PH.D. ${ }^{1,2}$
}

${ }^{1}$ Departments of Neurological Surgery and ${ }^{2}$ Pediatrics, University of California San Francisco, California; and ${ }^{3}$ Department of Neurological Surgery, Feinberg School of Medicine, Northwestern University, Chicago, Illinois

Object. Ependymomas are a common type of CNS tumor in children, although only $13 \%$ originate from the spinal cord. Aside from location and extent of resection, the factors that affect outcome are not well understood.

Methods. The authors performed a search of an institutional neuropathology database to identify all patients with spinal cord ependymomas treated over the past 20 years. Data on patient age, sex, clinical presentation, symptom duration, tumor location, extent of resection, use of radiation therapy, surgical complications, presence of tumor recurrence, duration of follow-up, and residual symptoms were collected. Pediatric patients were defined as those 21 years of age or younger at diagnosis. The extent of resection was defined by the findings of the postoperative MR images.

Results. A total of 24 pediatric patients with spinal cord ependymomas were identified with the following pathological subtypes: 14 classic (Grade II), 8 myxopapillary (Grade I), and 2 anaplastic (Grade III) ependymomas. Both anaplastic ependymomas originated in the intracranial compartment and spread to the spinal cord at recurrence. The mean follow-up duration for patients with classic and myxopapillary ependymomas was 63 and 45 months, respectively. Seven patients with classic ependymomas underwent gross-total resection (GTR), while 4 received subtotal resection (STR), 2 received STR as well as radiation therapy, and 1 received radiation therapy alone. All but 1 patient with myxopapillary ependymomas underwent GTR. Three recurrences were identified in the Grade II group at 45, 48, and 228 months. A single recurrence was identified in the Grade I group at 71 months. The mean progression-free survival (PFS) was 58 months in the Grade II group and 45 months in the Grade I group.

Conclusions. Extent of resection is an important prognostic factor in all pediatric spinal cord ependymomas, particularly Grade II ependymomas. These data suggest that achieving GTR is more difficult in the upper spinal cord, making tumor location another important factor. Although classified as Grade I lesions, myxopapillary ependymomas had similar outcomes when compared with classic (Grade II) ependymomas, particularly with respect to PFS. Longterm complications or new neurological deficits were rare. Among patients with long-term follow-up, those who underwent GTR had a recurrence rate of $20 \%$ compared with $40 \%$ among those with STR or biopsy only, suggesting that extent of resection is perhaps a more important prognostic factor than histological grade in predicting PFS, which has been suggested by other data in the literature. Given the relative paucity of these lesions, collaborative multiinstitutional studies are needed, and such efforts should also focus on molecular and genetic analysis to refine the current classification system.

(http://thejns.org/doi/abs/10.3171/2013.12.PEDS13383)

KEY Words • ependymoma $\bullet$ extent of resection $\bullet$ spine
progression-free survival $\bullet$ oncology

$\mathrm{E}$ PENDYMOMAS are among the most common CNS tumors in children and young adults. Their biological behavior can vary markedly from benign slowgrowing subependymomas to aggressive anaplastic epen-

\footnotetext{
Abbreviations used in this paper: GTR = gross-total resection; PFS = progression-free survival; STR = subtotal resection .

* Mr. Safaee and Dr. Oh contributed equally to this work.
}

dymomas. Among ependymomas in this age group, only $13 \%$ arise from the spinal cord, with the remaining found in the intracranial compartment (54\% infratentorial, 33\% supratentorial). ${ }^{27}$ The age at diagnosis for pediatric spinal cord ependymomas is usually between 10 and 14 years, compared with 5-8 years for children with intracranial ependymomas. ${ }^{27}$ Given the relative paucity of spinal cord ependymomas in this age group, long-term outcome data 
are difficult to obtain. Furthermore, because less than 5\% of primary CNS tumors in children occur in the spinal cord or cauda equina, outcome data following spinal cord tumor surgery are particularly limited..$^{11}$

The extent of resection for spinal cord ependymomas is an important prognostic factor affecting outcome. $3,6,8,44$ The role that other factors may play remains less well understood. For example, tumor location may determine the clinical presentation and may prompt early intervention, as compared with tumors arising in alternative locations. We recently reported that lesions in the upper spinal cord, defined as those in the cervicomedullary, cervical, and cervicothoracic cord, have a more favorable progressionfree survival (PFS) and overall survival compared with those in the lower spinal cord..$^{35}$ This finding was also confirmed in a series of adult spinal cord ependymomas. ${ }^{34}$ Recent genetic and molecular analysis has shown that location can also predict the tumor's biological behavior, particularly when comparing intracranial and spinal ependymomas. ${ }^{4,6,16,26,27}$ Histological grade has been described as an important prognostic factor in some studies, ${ }^{21,29,36}$ but not others. ${ }^{8,15,17,28,50}$ Not surprisingly, there are differences in survival associated with histological grade, with poor outcomes in patients who have anaplastic (WHO Grade III) lesions, while those with Grade I and Grade II ependymomas have a more favorable prognosis. ${ }^{40}$ Direct comparisons of outcomes among Grade I (myxopapillary) and Grade II (classic) spinal cord ependymomas in children are limited, but a recent systematic review found that extent of resection was a more important predictor of PFS than histological grade..$^{40}$

To investigate the surgical outcomes of spinal cord ependymomas in children we performed a single-institution, retrospective review examining patient demographics, clinical presentation, management, and tumor control.

\section{Methods}

\section{Data Abstraction}

Patients with spinal cord ependymomas treated between 1992 and 2012 were identified through a search of a neuropathology database at the University of California, San Francisco. Pediatric patients were defined as those less than or equal to 21 years of age at diagnosis. Review of electronic and paper medical records was used to abstract data including age, sex, clinical presentation, symptom duration, tumor location, extent of resection, use of radiation therapy, surgical complications, presence of tumor recurrence, duration of follow-up, and residual symptoms. Ependymomas were classified on the basis of pathological review as myxopapillary (WHO Grade I), classic (WHO Grade II), or anaplastic (WHO Grade III). The extent of resection was determined by reviewing the results of the postoperative MR image. The absence of residual enhancing tumor was defined as gross-total resection (GTR); patients with residual disease were classified as subtotal resection (STR). All activities were performed with permission from the Committee on Human Research at the University of California, San Francisco, which serves as the institutional review board.

\section{Results}

\section{Clinical Features}

A total of 178 spinal cord ependymomas were identified at our institution between 1992 and 2012. This cohort consisted of 107 males $(60 \%)$ and 71 females (40\%), with the following histological distribution: 125 (70\%) Grade II, 46 (26\%) Grade I, and 7 (4\%) anaplastic (Grade III) ependymomas. Among these patients, 24 spinal cord ependymomas (14\%) occurred in children with a mean age of $15.1 \pm 5.8$ years (range $2-21$ years). There were 9 females (38\%) and 15 males (63\%), with a histological distribution that included 14 Grade II ependymomas (58\%), 8 Grade I ependymomas (33\%), and 2 Grade III ependymomas (8\%). In both anaplastic ependymomas, the primary tumor was in an intracranial location and subsequently was identified in the spinal cord at recurrence. The clinical data for Grade I and II patients are summarized in Tables 1 and 2 .

Among 14 patients with Grade II ependymomas the mean age at presentation was 16.0 years (range 2-21 years) compared with 14.5 years (range $10-16$ years) for the 8 patients with Grade I ependymomas. The male to female ratio was 1.8:1 for Grade II ependymomas and 1:1 for Grade I ependymomas. Symptom duration was similar between groups with a mean of 8 months (range 1 week to 36 months) in patients with Grade II ependymomas and 6 months (range 1-18 months) for patients with Grade I ependymomas. In both groups, back pain was the most common presenting symptom, occurring in 9 of 14 Grade II and 6 of 8 Grade I patients. Five of 14 Grade II patients presented with weakness in an extremity and 3 presented with numbness (sensory loss). No Grade I patients presented with weakness, but a single patient experienced numbness in a lower extremity at diagnosis. Intraoperative motor and sensory evoked potentials were used in 7 cases but showed no association with extent of resection $(\mathrm{p}=0.73)$ or tumor recurrence $(\mathrm{p}=0.36)$.

\section{Tumor Control for Classic Ependymomas}

Among Grade II ependymomas included in our analysis, GTR was achieved in 7 patients (Fig. 1), STR in 4 patients, STR followed by radiation therapy in 2 patients, and biopsy with radiation in 1 patient. The mean follow-up time was 63 months (range 1-260 months) with 3 recurrences identified at 45,48 , and 228 months. The first recurrence occurred in a boy who presented with a thoracic spinal cord ependymoma at age 2 and underwent radiotherapy without resection at that time. At age 21 the patient presented with a 2-month history of lower-extremity weakness, bowel and bladder incontinence, and paresthesias. Imaging studies demonstrated a recurrent tumor, and the patient underwent STR of the lesion and is doing well more than 20 years (260 months) after the initial diagnosis. The second recurrence occurred in a 20 -year-old male who underwent STR with $54 \mathrm{~Gy}$ of fractionated radiotherapy for a large thoracolumbar ependymoma. At age 24 he presented with lower-extremity weakness and bowel and bladder incontinence. Imaging studies performed at that time demonstrated the presence of recurrent tumor, at which point he underwent a GTR. 


\section{Surgical outcomes in pediatric spinal cord ependymomas}

TABLE 1: Clinical outcomes in patients with classic (Grade II) ependymomas*

\begin{tabular}{|c|c|c|c|c|c|c|c|c|}
\hline $\begin{array}{l}\text { Case } \\
\text { No. }\end{array}$ & $\begin{array}{l}\text { Age (yrs), } \\
\text { Sex }\end{array}$ & Location & Presenting Symptoms & EOR & RT & Recurrence & PFS (mos) & $\begin{array}{l}\text { Clinical Follow-Up } \\
\text { (mos) }\end{array}$ \\
\hline 1 & $13, M$ & thoracolumbar & pain, weakness & GTR & no & no & 93 & 93 \\
\hline 2 & $17, \mathrm{M}$ & cervical & pain, weakness, sensory loss & GTR & no & no & 31 & 31 \\
\hline 3 & $18, \mathrm{~F}$ & conus & pain, sensory loss & GTR & no & no & 7 & 7 \\
\hline 4 & $8, \mathrm{~F}$ & cauda equina & $\begin{array}{l}\text { pain, paresthesias, bowel/ } \\
\text { bladder incontinence }\end{array}$ & STR & no & no & 143 & 143 \\
\hline 5 & $18, F$ & thoracic & weakness & STR & yes & no & 68 & 68 \\
\hline 6 & $3, \mathrm{M}$ & $\begin{array}{l}\text { cervicothoracic } \\
\text { (medulla to T2-3) }\end{array}$ & pain & STR & NA & lost to follow-up & 1 & 1 \\
\hline 7 & $2, \mathrm{M}$ & thoracic & NA & biopsy & yes & yes & 228 & 260 \\
\hline 8 & $20, M$ & cervical & weakness & STR & no & NA & NA & NA \\
\hline 9 & $21, \mathrm{M}$ & cervicomedullary & pain, sensory loss & STR & no & lost to follow-up & 6 & 6 \\
\hline 10 & $20, M$ & conus & pain & STR & yes & yes & 45 & 75 \\
\hline 11 & $21, \mathrm{M}$ & conus/cauda equina & weakness & GTR & no & no & 39 & 39 \\
\hline 12 & $21, \mathrm{~F}$ & conus & pain & GTR & no & yes & 48 & 49 \\
\hline 13 & $21, \mathrm{~F}$ & cervical & pain & GTR & no & no & 22 & 22 \\
\hline 14 & $21, \mathrm{M}$ & filum & incidental finding & GTR & no & no & 21 & 21 \\
\hline
\end{tabular}

* EOR = extent of resection, NA = not available; $\mathrm{RT}$ = radiation therapy.

The third recurrence occurred in a 21-year-old woman who underwent GTR of a tumor located within the conus that had myxopapillary features but was subsequently demonstrated to be a Grade II ependymoma. She developed worsening lower-extremity symptoms 48 months later and was found to have recurrent disease.

\section{Tumor Control for Myxopapillary Ependymomas}

Although classified as WHO Grade I lesions, pediatric Grade I ependymomas are considered more aggressive than their adult counterparts. However, in a recent systematic review we showed similar PFS among pediatric Grade I and II ependymomas, ${ }^{40}$ and thus sought to analyze our institutional data for comparison. In the Grade I group, 6 patients underwent GTR (Fig. 2), while 1 patient who had an STR also received fractionated radiotherapy to a final dose of $54 \mathrm{~Gy}$. The mean duration of follow up was 45 months (range 1-156 months). There was a single recurrence in a male who underwent GTR at age 16 and developed lower extremity pain 70 months later. An MRI performed at that time demonstrated a recurrent lesion in the lower spinal cord. The patient underwent GTR of the recurrent lesion with resolution of his lower-extremity pain. There were no new neurological deficits or major postoperative complications in this group, although 1 patient developed a pseudomeningocele that required surgical revision. All patients returned to their baseline state, or experienced resolution of their symptoms. Overall, there were no deaths in this study and the mean PFS for patients with Grade II and Grade I ependymomas was 58 months and 45 months, respectively.

\section{Complications}

Among patients with Grade II ependymomas, 2 developed worsening of their symptoms after surgery. The first was a 13-year-old boy who presented with 10 months of cervical neck pain. An MR image showed a complex intramedullary spinal cord lesion with solid and nodular cystic enhancing components. There were multiple foci of hemosiderin deposition within the mass, suggesting

TABLE 2: Clinical outcomes in patients with myxopapillary (Grade I) ependymomas

\begin{tabular}{cclllllrr}
\hline $\begin{array}{c}\text { Case } \\
\text { No. }\end{array}$ & $\begin{array}{c}\text { Age (yrs), } \\
\text { Sex }\end{array}$ & Location & $\begin{array}{c}\text { Presenting } \\
\text { Symptoms }\end{array}$ & EOR & RT & Recurrence & $\begin{array}{c}\text { PFS } \\
\text { (mos) }\end{array}$ & $\begin{array}{c}\text { Clinical Follow-Up } \\
\text { (mos) }\end{array}$ \\
\hline 1 & $10, \mathrm{~F}$ & filum & pain & GTR & no & no & 156 & 156 \\
2 & $14, \mathrm{~F}$ & filum/conus & pain & GTR & no & no & 11 & 11 \\
3 & $15, \mathrm{M}$ & filum & pain, sensory loss & GTR & no & lost to follow-up & 2 & 2 \\
4 & $15, \mathrm{M}$ & filum/conus & pain & GTR & no & lost to follow-up & 1 & 1 \\
5 & $16, \mathrm{M}$ & cauda equina & pain & STR & yes & no & 76 & 76 \\
6 & $16, \mathrm{M}$ & filum & NA & GTR & no & yes & 70 & 71 \\
7 & $14, \mathrm{~F}$ & lumbar & NA & NA & NA & NA & NA & NA \\
8 & $16, \mathrm{~F}$ & cauda equina & pain & GTR & no & lost to follow-up & 1 & 1 \\
\hline
\end{tabular}



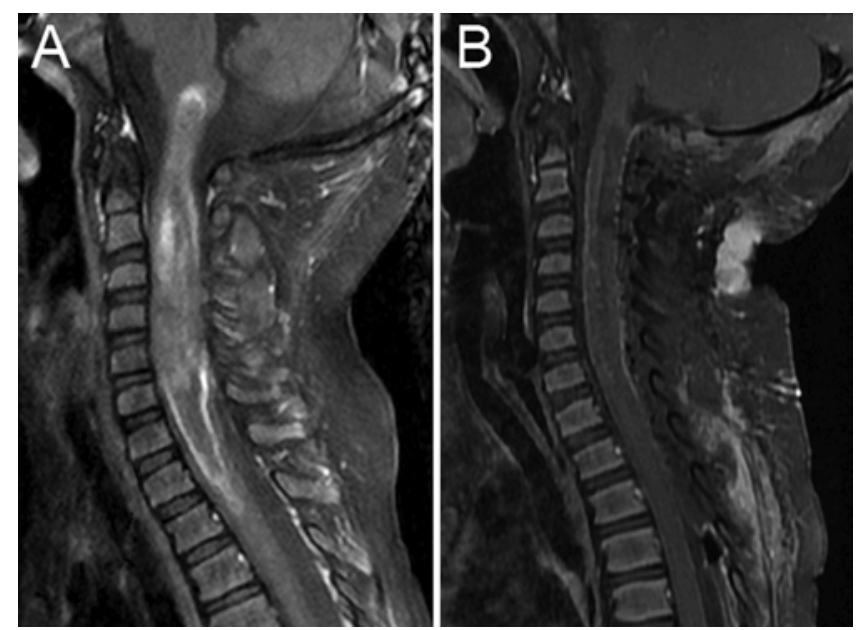

Fig. 1. Case 6 (from Table 1). Sagittal pre- (A) and postoperative (B) T1-weighted MR images after contrast administration from a patient with a spinal Grade II (classic) ependymoma. This 3-year-old boy presented to an outside hospital with several weeks of pain and progressive weakness that left the patient unable to ambulate. The preoperative images of the cervical spine demonstrated an expansile intramedullary lesion within the cervical cord that extended cranially to the medulla and caudally to the level of T2-3 (A). The lesion exhibited heterogeneous enhancement and appeared centrally located with a rim of normal cord circumferentially. The patient underwent STR of this lesion (B).

prior hemorrhage. He underwent T7-L3 laminectomies and GTR of this lesion, but after surgery was found to have decreased sensation and proprioception in his lower extremities and a neurogenic bowel and bladder. The patient was last seen 92 months after surgery and demonstrated full strength in both upper and lower extremities, but persistently decreased sensation and proprioception in his lower extremities along with a neurogenic bowel and bladder.

The second patient was a 21-year-old woman who presented with 3 months of neck pain and paresthesias in the upper extremity. She was found to have an expansile cystic lesion in the cervical cord that extended from the cervicomedullary junction to C-7. The lesion also contained a significant, solid enhancing component from $\mathrm{C}-1$ to $\mathrm{C}-3$. She underwent a C-1 laminectomy and C2-4 laminoplasty for GTR of this intramedullary classic ependymoma. Postoperatively she had normal strength in her upper and lower extremities, but decreased proprioception that limited her ability to ambulate without assistance. She is otherwise healthy without evidence of disease 22 months after surgery.

\section{Discussion}

Spinal cord ependymomas are more common in adults and thus outcome data in pediatric patients are limited. We present a retrospective single-institution series of pediatric spinal cord ependymomas treated over the past 20 years. Extent of resection is an important factor in tumor control and survival, particularly in Grade II ependymomas. ${ }^{40}$ Among the 22 pediatric spinal cord ependymomas included in this study, 13 underwent GTR (7 of 14 Grade II and 6 of 8 Grade I ependymomas).

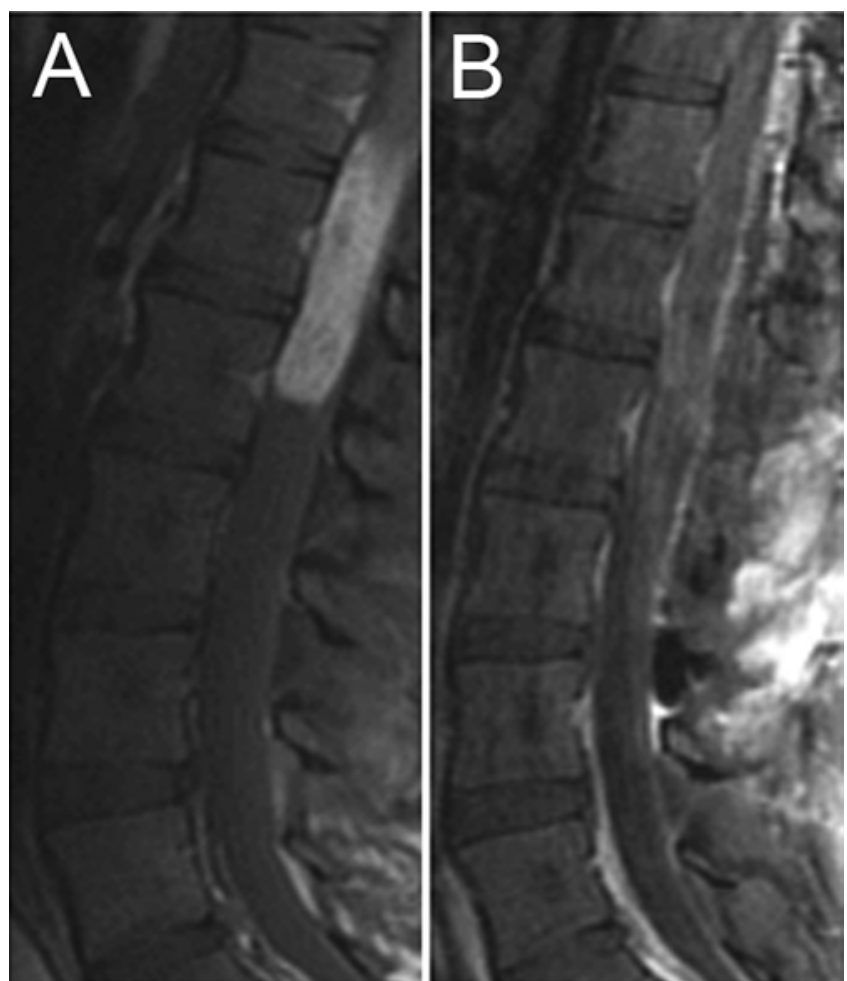

FIG. 2. Case 2 (from Table 2). Sagittal pre- (A) and postoperative (B) T1-weighted MR images after contrast administration from a patient with a spinal Grade I (myxopapillary) ependymoma. This 14-year-old girl presented with 1 month of back pain with radiation to the left lower extremity. Preoperative images of the lumbar spine demonstrated an enhancing lesion near the conus with displacement of the conus and nerve roots of the cauda equina posteriorly $(A)$. She underwent T12-L3 laminectomies with GTR of this lesion. Her symptoms resolved postoperatively (B) and she remains free of disease nearly 12 months after surgery.

Myxopapillary ependymomas occurred exclusively in the conus/cauda equina or filum, but among Grade II ependymomas, half were located in the upper spinal cord (cervicomedullary to thoracic) and half in the lower spinal cord (thoracolumbar to conus/cauda equina or filum). There was a lower rate of GTR among Grade II ependymomas in the upper spinal cord ( 2 of 7) compared with the lower spinal cord (5 of 7), suggesting that GTR is more difficult in this location. Rates of GTR among Grade I and Grade II ependymomas of the lower spinal cord were similar, although this may be confounded by Grade I ependymomas of the filum, which are generally associated with higher rates of GTR. Overall, GTR provided good tumor control, with recurrences occurring in only 2 of 10 cases with long-term follow-up (1 Grade I and 1 Grade II ependymoma) at 70 and 48 months, respectively. In patients with long-term follow-up who had biopsy or STR, the tumors progressed in 2 of 5 cases (all Grade II ependymomas) at 45 and 228 months.

A secondary goal of this study was to compare our institutional outcomes of Grade I ependymomas in children to those reported in the literature. Although there is evidence that Grade I ependymomas are more aggressive in children compared with adults, $, 538,45$ our institutional experience suggests that GTR can be achieved safely, in 


\section{Surgical outcomes in pediatric spinal cord ependymomas}

most patients (6 of 8 cases), and results in good tumor control without the need for adjuvant radiotherapy. A recent literature review on pediatric spinal cord myxopapillary ependymomas reported GTR in $60 \%$ of cases, but similar recurrence rates when comparing GTR (40\%) to STR $(43 \%)$ at an average follow-up of 77 months. ${ }^{48}$ Furthermore, a recent review of our institutional data suggests that extent of resection is associated with improved tumor control among Grade II ependymomas, but not Grade I ependymomas. ${ }^{49}$ The study also reported 7 deaths (8\%), while we had no deaths due to surgery or disease among both Grade I and Grade II ependymomas.

The indications and utility of adjuvant therapies for Grade I ependymomas are also an area of ongoing study. Several studies have demonstrated improved 5- and 10year tumor control rates among Grade I ependymoma patients who received surgery as well as radiotherapy compared with surgery alone, even in cases of GTR.1,2,38 Furthermore, patients receiving high-dose radiotherapy had prolonged PFS compared with those receiving standard doses. ${ }^{38}$ Since Grade I ependymoma recurrences tend to be local, they can generally be treated by resection with or without radiotherapy. Radiotherapy may prove to be a useful adjunct and allow for less aggressive surgery with lower morbidity among patients with Grade I ependymomas. There are few studies evaluating the role of radiotherapy for spinal classic ependymomas in children, although some data suggest that GTR alone should be the treatment objective, even for recurrent tumors, because STR with radiotherapy appears to offer little advantage over GTR.7,20,24 Some argue that radiotherapy should be reserved for anaplastic lesions or residual tumor after reoperation, particularly in children in whom it is unclear if the potential benefits of radiotherapy outweigh the risks on the developing nervous and osseous tissues.

Although our sample size precludes a more thorough statistical analysis, the results provide insight toward the prognostic value of tumor grade and extent of resection. The mean PFS for patients with Grade II and Grade I ependymomas was 58 and 45 months, respectively. In another report of pediatric patients with spinal cord ependymomas, we observed no significant difference in PFS across histological grade (Grades I, II, and III). ${ }^{40}$ Patients who underwent GTR, however, had significantly longer PFS compared with those who underwent STR, regardless of tumor grade. ${ }^{40}$ Similarly, our institutional data show a recurrence rate of $20 \%$ ( 2 of 10) among patients who underwent GTR compared with $40 \%$ (2 of 5) among patients who underwent STR or biopsy. Taken together, our institutional experience supports the notion that extent of resection is an important factor in predicting tumor control and may be more important that tumor histology, particularly when comparing myxopapillary to classic ependymomas. Because there were no deaths in our cohort we are unable to comment on survival with spinal cord ependymomas, but our systematic review suggests that age, extent of resection, and anaplastic histology are the most important factors associated with survival. ${ }^{40}$

In a relatively large study of patients with spinal cord ependymoma with long-term follow-up, Gomez et al. reported 10- and 15-year tumor control rates of 50\% and $46 \%$, respectively, suggesting that treatment failure is relatively common. ${ }^{14}$ The average time to recurrence in our cohort of Grade I and II ependymomas was 98 months, an observation that emphasizes the need for long-term follow-up. Collin's Law (the risk of recurrence is highest for a time equal to age at surgery plus 9 months) provides a useful guideline, but our practice over the past 20 years has generally been to obtain imaging every 6 months for the first 2-3 years, followed by clinical surveillance every 1-2 years or upon presentation of new or worsening symptoms. At recurrence, our practice has been to attempt GTR or STR with radiotherapy. In 2 Grade II patients with local recurrence and long-term follow-up, 1 received GTR alone and remains free of disease 30 months after the second surgery and 75 months from initial diagnosis. A second patient underwent STR with radiotherapy at recurrence and remains progression free 32 months after the second surgery and 260 months after initial diagnosis. It should be emphasized that because Grade II ependymomas are generally intramedullary and Grade I ependymomas occur almost exclusively in the conus or cauda equina, that direct comparisons of outcomes among patients with these lesions should be performed cautiously. We do note, however, that among patients treated at our institution with at least 1 year of follow-up, recurrence rates were nearly identical: 3 (30\%) of 10 among Grade II ependymomas, and 1 (33\%) of 3 among Grade I ependymomas.

Children are believed to have a higher chance of developing spinal deformity after surgery due to the horizontal orientation of their facet joints, increased ligament laxity, and immature skeletal system. ${ }^{12,32,37,41,43}$ Spinal cord tumor resection is complicated by spinal deformity in approximately $10 \%$ of adults compared with $16 \%-100 \%$ of pediatric patients among several series., ${ }^{9,13,37,39,51}$ Some have suggested that postlaminectomy deformity can be minimized by use of laminoplasty, but there is little convincing data to support this practice. , $^{95,30,33,46,51}$ Our small sample size prevented a detailed analysis, but of the patients included in this study, 70\% underwent laminectomy compared with $30 \%$ who had laminoplasty. The 1 patient who developed postoperative deformity underwent T3-L3 laminotomies. In general, the surgical approach should balance the need for maximal safe resection with preservation of spinal stability.

Intraoperative neuromonitoring is increasingly used in spine surgery, particularly for intramedullary spinal cord tumors. We were unable to detect a difference in extent of resection or tumor recurrence rates among patients treated with intraoperative neuromonitoring compared with those without. In a prospective series of intramedullary spinal cord tumors, Morota et al. ${ }^{31}$ found that motor evoked potential monitoring was associated with good outcomes in adults, but not children, while other authors have commented on the extent to which intraoperative neuromonitoring changes drive intraoperative decision making. ${ }^{22,23,47}$ Although some data have demonstrated the utility of intraoperative neuromonitoring, it should be considered as an adjunct during resection of all intramedullary spinal cord tumors, with a careful understanding of its limitations. ${ }^{10,18,19,42}$ 
This study is a retrospective, single-institution analysis and therefore subject to certain limitations. Retrospective analysis introduces recall bias and difficulty controlling for confounders, but randomized prospective studies are difficult for surgical diseases, particularly those as rare as pediatric spinal cord ependymomas. The small sample size precludes a more thorough statistical analysis, but the number of patients in this study does compare favorably with other contemporary, single-institution series. Four patients with Grade I ependymomas chose to maintain surveillance imaging and follow-up care at an outside institution, which is a persistent challenge because our patient base consists mostly of referrals for tertiary care. As a result, our data may represent an underestimate of the true recurrence rate for pediatric Grade I ependymomas. Despite these limitations, our findings are important given the low incidence of spinal cord ependymomas in children, the long follow-up among patients who chose to maintain care at our center, and the need for more outcomes data in this disease.

\section{Conclusions}

Although representing one of the most frequently occurring spinal cord tumors in adults, ependymomas of the pediatric spinal cord are relatively uncommon. Classic ependymomas of the spine are likely to have distinct biological features, but respond well to surgery alone, with tumor location and extent of resection representing important prognostic factors. We note that myxopapillary ependymomas can be removed safely with minimal morbidity and that good tumor control can be achieved with resection alone. Limited follow-up prevents us from drawing more definitive conclusions, but our data suggest that extent of resection is an important prognostic factor in predicting tumor control, perhaps even more so than histological grade when comparing myxopapillary to classic ependymomas. Future studies must be collaborative and multiinstitutional in nature to determine the role of radiotherapy for spinal cord ependymomas, and include genetic analyses to refine tumor classification and increase our understanding of the underlying biology.

\section{Disclosure}

Dr. Mummaneni has received royalties from DePuy Spine, Quality Medical Publishers, and Thieme Publishers, has direct stock ownership in Spinicity, and has received honoraria from Globus. Dr. Ames serves as a consultant to DePuy, Stryker, and Medtronic; has direct stock ownership in Visualase, Doctors Research Group, and Baxano Surgery; is a patent holder for Fish \& Richardson, P.C.; and has received royalties from Lanx and Aesculap. Dr. Chou has received honoraria from Depuy and Orthofix, and serves as a consultant to Globus.

Author contributions to the study and manuscript preparation include the following. Conception and design: Gupta, Safaee, Oh, Parsa. Acquisition of data: Gupta, Safaee, Oh, Parsa. Analysis and interpretation of data: Gupta, Safaee, Oh, Parsa. Drafting the article: Gupta, Safaee, Oh, Parsa. Critically revising the article: all authors. Reviewed submitted version of manuscript: all authors. Approved the final version of the manuscript on behalf of all authors: Gupta. Statistical analysis: Gupta, Safaee, Oh, Parsa. Administrative/technical/material support: Gupta, Parsa. Study supervision: Gupta, Parsa.

\section{References}

1. Agbahiwe HC, Wharam M, Batra S, Cohen K, Terezakis SA: Management of pediatric myxopapillary ependymoma: the role of adjuvant radiation. Int J Radiat Oncol Biol Phys 85:421-427, 2013

2. Akyurek S, Chang EL, Yu TK, Little D, Allen PK, McCutcheon I, et al: Spinal myxopapillary ependymoma outcomes in patients treated with surgery and radiotherapy at M.D. Anderson Cancer Center. J Neurooncol 80:177-183, 2006

3. Allen JC, Siffert J, Hukin J: Clinical manifestations of childhood ependymoma: a multitude of syndromes. Pediatr Neurosurg 28:49-55, 1998

4. Armstrong TS, Vera-Bolanos E, Bekele BN, Aldape K, Gilbert MR: Adult ependymal tumors: prognosis and the M. D. Anderson Cancer Center experience. Neuro Oncol 12:862870,2010

5. Bagley CA, Wilson S, Kothbauer KF, Bookland MJ, Epstein F, Jallo GI: Long term outcomes following surgical resection of myxopapillary ependymomas. Neurosurg Rev 32:321-334, 2009

6. Benesch M, Weber-Mzell D, Gerber NU, von Hoff K, Deinlein F, Krauss J, et al: Ependymoma of the spinal cord in children and adolescents: a retrospective series from the HIT database. Clinical article. J Neurosurg Pediatr 6:137-144, 2010

7. Constantini S, Miller DC, Allen JC, Rorke LB, Freed D, Epstein FJ: Radical excision of intramedullary spinal cord tumors: surgical morbidity and long-term follow-up evaluation in 164 children and young adults. J Neurosurg 93 (2 Suppl): 183-193, 2000

8. Conter C, Carrie C, Bernier V, Geoffray A, Pagnier A, Gentet $\mathrm{JC}$, et al: Intracranial ependymomas in children: society of pediatric oncology experience with postoperative hyperfractionated local radiotherapy. Int J Radiat Oncol Biol Phys 74:1536-1542, 2009

9. de Jonge T, Slullitel H, Dubousset J, Miladi L, Wicart P, Illés T: Late-onset spinal deformities in children treated by laminectomy and radiation therapy for malignant tumours. Eur Spine J 14:765-771, 2005

10. Deletis V, Sala F: The role of intraoperative neurophysiology in the protection or documentation of surgically induced injury to the spinal cord. Ann N Y Acad Sci 939:137-144, 2001

11. Dolecek TA, Propp JM, Stroup NE, Kruchko C: CBTRUS statistical report: primary brain and central nervous system tumors diagnosed in the United States in 2005-2009. Neuro Oncol 14 (Suppl 5):v1-v49, 2012

12. Fassett DR, Clark R, Brockmeyer DL, Schmidt MH: Cervical spine deformity associated with resection of spinal cord tumors. Neurosurg Focus 20(2):E2, 2006

13. Fraser RD, Paterson DC, Simpson DA: Orthopaedic aspects of spinal tumors in children. J Bone Joint Surg Br 59:143-151, 1977

14. Gomez DR, Missett BT, Wara WM, Lamborn KR, Prados MD, Chang S, et al: High failure rate in spinal ependymomas with long-term follow-up. Neuro Oncol 7:254-259, 2005

15. Grill J, Le Deley MC, Gambarelli D, Raquin MA, Couanet D, Pierre-Kahn A, et al: Postoperative chemotherapy without irradiation for ependymoma in children under 5 years of age: a multicenter trial of the French Society of Pediatric Oncology. J Clin Oncol 19:1288-1296, 2001

16. Helseth A, Mørk SJ: Primary intraspinal neoplasms in Norway, 1955 to 1986. A population-based survey of 467 patients. J Neurosurg 71:842-845, 1989

17. Jaing TH, Wang HS, Tsay PK, Tseng CK, Jung SM, Lin KL, et al: Multivariate analysis of clinical prognostic factors in children with intracranial ependymomas. J Neurooncol 68:255261,2004

18. Kothbauer K, Deletis V, Epstein FJ: Intraoperative spinal cord 
monitoring for intramedullary surgery: an essential adjunct. Pediatr Neurosurg 26:247-254, 1997

19. Kothbauer KF, Deletis V, Epstein FJ: Motor-evoked potential monitoring for intramedullary spinal cord tumor surgery: correlation of clinical and neurophysiological data in a series of 100 consecutive procedures. Neurosurg Focus 4(5):e1, 1998

20. Lee SH, Chung CK, Kim CH, Yoon SH, Hyun SJ, Kim KJ, et al: Long-term outcomes of surgical resection with or without adjuvant radiation therapy for treatment of spinal ependymoma: a retrospective multicenter study by the Korea Spinal Oncology Research Group. Neuro Oncol 15:921-929, 2013

21. Massimino M, Gandola L, Giangaspero F, Sandri A, Valagussa P, Perilongo G, et al: Hyperfractionated radiotherapy and chemotherapy for childhood ependymoma: final results of the first prospective AIEOP (Associazione Italiana di Ematologia-Oncologia Pediatrica) study. Int J Radiat Oncol Biol Phys 58:1336-1345, 2004

22. McCormick PC, Stein BM: Intramedullary tumors in adults. Neurosurg Clin N Am 1:609-630, 1990

23. McCormick PC, Torres R, Post KD, Stein BM: Intramedullary ependymoma of the spinal cord. J Neurosurg 72:523-532, 1990

24. McGirt MJ, Chaichana KL, Atiba A, Attenello F, Woodworth GF, Jallo GI: Neurological outcome after resection of intramedullary spinal cord tumors in children. Childs Nerv Syst 24:93-97, 2008

25. McGirt MJ, Garcés-Ambrossi GL, Parker SL, Sciubba DM, Bydon A, Wolinksy JP, et al: Short-term progressive spinal deformity following laminoplasty versus laminectomy for resection of intradural spinal tumors: analysis of 238 patients. Neurosurgery 66:1005-1012, 2010

26. McGuire CS, Sainani KL, Fisher PG: Both location and age predict survival in ependymoma: a SEER study. Pediatr Blood Cancer 52:65-69, 2009

27. McGuire CS, Sainani KL, Fisher PG: Incidence patterns for ependymoma: a surveillance, epidemiology, and end results study. Clinical article. J Neurosurg 110:725-729, 2009

28. McLaughlin MP, Marcus RB Jr, Buatti JM, McCollough WM, Mickle JP, Kedar A, et al: Ependymoma: results, prognostic factors and treatment recommendations. Int J Radiat Oncol Biol Phys 40:845-850, 1998

29. Merchant TE, Jenkins JJ, Burger PC, Sanford RA, Sherwood $\mathrm{SH}$, Jones-Wallace D, et al: Influence of tumor grade on time to progression after irradiation for localized ependymoma in children. Int J Radiat Oncol Biol Phys 53:52-57, 2002

30. Meyer NJ, Flatley TJ, Dunn DD: Superiorly based laminoplasty in children: average 6.8-year follow-up of 21 patients. J Spinal Disord Tech 16:156-162, 2003

31. Morota N, Deletis V, Constantini S, Kofler M, Cohen H, Epstein FJ: The role of motor evoked potentials during surgery for intramedullary spinal cord tumors. Neurosurgery 41:1327-1336, 1997

32. Nagasawa DT, Smith ZA, Cremer N, Fong C, Lu DC, Yang I: Complications associated with the treatment for spinal ependymomas. Neurosurg Focus 31(4):E13, 2011

33. Nowinski GP, Visarius H, Nolte LP, Herkowitz HN: A biomechanical comparison of cervical laminaplasty and cervical laminectomy with progressive facetectomy. Spine (Phila Pa 1976) 18:1995-2004, 1993

34. Oh MC, Kim JM, Kaur G, Safaee M, Sun MZ, Singh A, et al: Prognosis by tumor location in adults with spinal ependymomas. Clinical article. J Neurosurg Spine 18:226-235, 2013

35. Oh MC, Sayegh ET, Safaee M, Sun MZ, Kaur G, Kim JM, et al: Prognosis by tumor location for pediatric spinal cord ependymomas. Clinical article. J Neurosurg Pediatr 11:282-288, 2013

36. Oya N, Shibamoto Y, Nagata Y, Negoro Y, Hiraoka M: Postoperative radiotherapy for intracranial ependymoma: analysis of prognostic factors and patterns of failure. $\mathbf{J}$ Neurooncol 56:87-94, 2002

37. Papagelopoulos PJ, Peterson HA, Ebersold MJ, Emmanuel PR, Choudhury SN, Quast LM: Spinal column deformity and instability after lumbar or thoracolumbar laminectomy for intraspinal tumors in children and young adults. Spine (Phila Pa 1976) 22:442-451, 1997

38. Pica A, Miller R, Villà S, Kadish SP, Anacak Y, Abusaris H, et al: The results of surgery, with or without radiotherapy, for primary spinal myxopapillary ependymoma: a retrospective study from the rare cancer network. Int J Radiat Oncol Biol Phys 74:1114-1120, 2009

39. Reimer R, Onofrio BM: Astrocytomas of the spinal cord in children and adolescents. J Neurosurg 63:669-675, 1985

40. Safaee M, Oh MC, Kim JM, Aranda D, Tarapore PE, Cage TA, et al: Histologic grade and extent of resection are associated with survival in pediatric spinal cord ependymomas. Childs Nerv Syst 29:2057-2064, 2013

41. Saito T, Yamamuro T, Shikata J, Oka M, Tsutsumi S: Analysis and prevention of spinal column deformity following cervical laminectomy. I. Pathogenetic analysis of postlaminectomy deformities. Spine (Phila Pa 1976) 16:494-502, 1991

42. Sala F, Krzan MJ, Deletis V: Intraoperative neurophysiological monitoring in pediatric neurosurgery: why, when, how? Childs Nerv Syst 18:264-287, 2002

43. Sciubba DM, Chaichana KL, Woodworth GF, McGirt MJ, Gokaslan ZL, Jallo GI: Factors associated with cervical instability requiring fusion after cervical laminectomy for intradural tumor resection. J Neurosurg Spine 8:413-419, 2008

44. Smyth MD, Horn BN, Russo C, Berger MS: Intracranial ependymomas of childhood: current management strategies. Pediatr Neurosurg 33:138-150, 2000

45. Sonneland PR, Scheithauer BW, Onofrio BM: Myxopapillary ependymoma. A clinicopathologic and immunocytochemical study of 77 cases. Cancer 56:883-893, 1985

46. Spiegel DA, Loder RT, Alley KA, Rowley S, Gutknecht S, Smith-Wright DL, et al: Spinal deformity following selective dorsal rhizotomy. J Pediatr Orthop 24:30-36, 2004

47. Steinbok P, Cochrane DD, Poskitt K: Intramedullary spinal cord tumors in children. Neurosurg Clin N Am 3:931-945, 1992

48. Stephen JH, Sievert AJ, Madsen PJ, Judkins AR, Resnick AC, Storm PB, et al: Spinal cord ependymomas and myxopapillary ependymomas in the first 2 decades of life: a clinicopathological and immunohistochemical characterization of 19 cases. Clinical article. J Neurosurg Pediatr 9:646-653, 2012

49. Tarapore PE, Modera P, Naujokas A, Oh MC, Amin B, Tihan $\mathrm{T}$, et al: Pathology of spinal ependymomas: an institutional experience over 25 years in 134 patients. Neurosurgery 73: 247-255, 2013

50. Timmermann B, Kortmann RD, Kühl J, Meisner C, Slavc I, Pietsch T, et al: Combined postoperative irradiation and chemotherapy for anaplastic ependymomas in childhood: results of the German prospective trials HIT 88/89 and HIT 91. Int J Radiat Oncol Biol Phys 46:287-295, 2000

51. Yeh JS, Sgouros S, Walsh AR, Hockley AD: Spinal sagittal malalignment following surgery for primary intramedullary tumours in children. Pediatr Neurosurg 35:318-324, 2001

Manuscript submitted July 27, 2013.

Accepted December 26, 2013.

Please include this information when citing this paper: published online February 7, 2014; DOI: 10.3171/2013.12.PEDS13383.

Address correspondence to: Nalin Gupta, M.D.,Ph.D., Department of Neurological Surgery, University of California San Francisco, 505 Parnassus Ave., Rm. M779, San Francisco, CA 94143-0112. email: guptan@neurosurg.ucsf.edu. 